\title{
Stage II Superficial Spreading Melanoma AJCC v6 and v7
}

National Cancer Institute

\section{Source}

National Cancer Institute. Stage /l Superficial Spreading Melanoma A/CC v6 and v7. NCI

Thesaurus. Code C8791.

Stage II includes: IIA: (T 2b, N0, M0); (T3a, N0, M0); IIB: (T3b, NO, M0); (T4a, N0, M0); IIC: (T4b, N0, M0). T2b: Cutaneous melanoma with a tumor measuring 1.01-2.0 mm in thickness, with ulceration. T3a: Cutaneous melanoma with a tumor measuring 2.01-4.0 $\mathrm{mm}$ in thickness, without ulceration. T3b: Cutaneous melanoma with a tumor measuring 2.01-4.0 mm in thickness, with ulceration. T4a: Cutaneous melanoma with a tumor measuring more than $4.0 \mathrm{~mm}$ in thickness, without ulceration. T4b: Cutaneous melanoma with a tumor measuring more than $4.0 \mathrm{~mm}$ in thickness, with ulceration. N0: No regional lymph node metastases. M0: No detectable evidence of distant metastases. (from AJCC 6th and 7th Ed.) 